\title{
PEMBANGKIT PULSA ORDE NANO/MIKRO-DETIK UNTUK PEMICU TRANSDUSER ULTRASONIK
}

\author{
DARMAWAN HIDAYAT *, MUHAMMAD EGA SIMATUPANG, NENDI SUHENDI, \\ BAMBANG MUKTI WIBAWA \\ Departemen Teknik Elektro, FMIPA, Universitas Padjadjaran \\ Jl. Raya Bandung-Sumedang Km.21 Jatinangor 45363, Sumedang, Jawa Barat \\ *email : darmawan.hidayat@unpad.ac.id
}

\begin{abstract}
Abstrak. Pulsa dengan lebar sempit (orde nano- hingga mikro- detik) banyak diperlukan untuk berbagai aplikasi, seperti teknologi pengolahan pangan, pembangkitan plasma, pemicu transduser ultrasonik frekuensi tinggi, elektroporasi dan sebagainya. Makalah ini melaporkan hasil rancang bangun oleh grup riset kami pembangkit pulsa dengan lebar hingga 75 nanodetik untuk digunakan sebagai pemicu transduser ultrasonik 1 Mhz. Pulsa level TTL dibangkitkan dari sebuah astable multivibrator (NE555) dengan pengaturan interval antar-pulsa variabel hingga satu mikrodetik. Selanjutnya, tepi positif pulsa tersebut memicu rangkaian Schmitt trigger (SN74121) yang diatur pada mode kerja oneshot multivibrator dengan lebar pulsa orde $\sim 75$ nanodetik. Sebuah Schmitt trigger kedua (MC33151) yang bekerja pada tegangan catu daya $+18 \mathrm{~V}$ mengubah level tegangan TTL menjadi $+18 \mathrm{~V}$ guna mengaktifkan saklar tegangan tinggi pada tingkat berikutnya. Hasil pengujian menunjukkan generator dapat membangkitkan pulsa repetitif tegangan $+18 \mathrm{~V}$ dengan lebar pulsa variabel hingga 75 nanodetik. Hasil ini menyimpulkan bahwa sistem yang dibangun dapat membangkitkan pulsa sesuai dengan rancangan.
\end{abstract}

Kata kunci : generator pulsa, lebar pulsa, nanodetik, multivibrator, Schmitt trigger

\begin{abstract}
Nano-to-millisecond order high-voltage pulse generators are necessary in the wide range of applications, including ultrasonic wave generation, medical and biological researches such as medical imaging and chemical-free bacterial remediation, etc. This paper reports the generation of repetitive nanosecond adjustable pulse width pulses for the excitation of a 1-MHz ultrasonic transducer. An astable multivibrator (NE555) generated TTL pulses up to one microsecond repetition interval. The positive edges of generated pulses triggered the next inverting Schmitt trigger circuit (SN74121) which set as a one-shot multivibrator adjusted at 75 nanosecond TTL pulse width. The second inverting Schmitt trigger circuit (MC33151) converted these TTL pulses into +18 V nonTTL pulses for driving the final high voltage MOSFET gate. The test results showed the integrated-circuit enable to generate repetitive $+18 \mathrm{~V}$ pulses with up to 75 nanosecond adjustable pulse width.
\end{abstract}

Keywords : pulse generator, width pulse, nanosecond, multivibrator, Schmitt trigger

\section{Pendahuluan}

Generator daya pulsa lebar singkat digunakan pada banyak aplikasi seperti militer, medis, inspeksi objek, pengukuran besaran fisis dan berbagai aplikasi kehidupan $[1,2]$. Berbagai rangkaian pembentuk pulsa banyak digunakan untuk membangkitkan pulsa singkat tegangan tinggi [3-5]. Dalam pembangkitan gelombang ultrasonik frekuensi tinggi, generator pulsa dengan lebar pulsa singkat (orde mili- hingga nano-detik) diperlukan untuk eksitasi transduser frekuensi tinggi (orde lebih dari $1 \mathrm{MHz}$ ) karena lebar pulsa singkat mengandung lebar pita frekuensi yang lebar [6,7]. Sebelum teknologi semikonduktor berkembang, implementasi 
rangkaian generator ini sangat kompleks dan memerlukan komponen-komponen mahal. Seiring kemajuan perkembangan teknologi semikonduktor, terutama produksi transistor efek medan (MOSFET) yang memiliki kecepatan tinggi, rangkaian generator pulsa daya cepat tegangan tinggi dapat direalisasikan dengan lebih sederhana dan murah [8-10].

Oleh karena itu, rangkaian yang dapat membangkitkan pulsa tegangan tinggi dengan lebar pulsa orde nanodetik menjadi sangat penting dalam teknologi berbasis gelombang ultrasonik. Makalah ini menyajikan desain dan implementasi generator pulsa cepat orde hingga 75 nanodetik dengan aras tegangan non-TTL $+18 \mathrm{~V}$ yang dibangun dari komponen multivibrator astabil, multivibrator monostabil dan pemicu Schmitt (Schmitt trigger) kecepatan tinggi. Keluaran generator ini akan digunakan untuk menggerakkan MOSFET untuk pensaklaran (switching) tegangan tinggi..

\section{Metode Penelitian}

Prinsip utama generator ini adalah pembangkitan pulsa kotak TTL dengan interval dan lebar pulsa yang dapat diatur. Pulsa-pulsa ini memicu rangkaian Schmitt trigger kecepatan tinggi yang telah diatur pada lebar pulsa variabel hingga 75 nanodetik aras tegangan non-TTL $+18 \mathrm{~V}$. Gambar 1 memperlihatkan rangkaian lengkap keseluruhan tahap pembangkitan pulsa dan bentuk konversi pulsa pada setiap tahap rangkaian [11,12]. Garis putus-putus adalah rangkaian pembangkit pulsa yang dikaji pada makalah ini untuk menggerakkan MOSFET tegangan tinggi di tahap berikutnya. Pertama-tama, rangkaian multivibrator astabil yang dibangun dari IC NE555 membangkitkan pulsa kotak TTL. Lebar pulsa, $t_{1}$ dan interval repetisi, $t_{2}$ ditentukan oleh nilai $R_{1}, R_{2}$ dan $C_{1}$ (Gambar 1.b) masing-masing dihitung dengan Persamaan 1 dan 2. Perioda dan frekuensi sinyal pulsa keluaran dihitung melalui Persamaan 4 dan 5 [13].

$$
\begin{array}{r}
t_{1}=0,693\left(R_{1}+R_{2}\right) \cdot C_{2} \\
t_{2}=0,693 \times R_{2} \times C_{2} \\
T=t_{1}+t_{2}=0,693\left(R_{1}+2 R_{2}\right) \cdot C_{2} \\
f=\frac{1}{T}=\frac{1,44}{\left(R_{1}+2 R_{2}\right) \cdot C_{2}}
\end{array}
$$

Dengan pemilihan nilai $R_{1}, R_{2}$ dan $C_{2}$ masing-masing adalah $500 \mathrm{ohm}$ dan $100 \mathrm{ohm}$, dan $0,1 \mu \mathrm{F}$, maka besar $t_{1}$ dan $t_{2}$ adalah $4,16 \times 10^{-5}$ dan $6,93 \times 10^{-6}$ detik atau frekuensi pulsa adalah $20164,31 \mathrm{~Hz}$. Resistor $R_{2}$ dipasang sebagai potensiometer untuk variasi interval repetisi pulsa. Pulsa keluaran ini kemudian dimasukkan ke rangkaian multivibrator monostabil (SN74121) mode one-shot dengan input Schmitt trigger tepi positif. Dengan begitu, rangkaian ini akan menghasilkan pulsa TTL ketika masukannya menerima tepi positif pulsa dari rangkaian multivibrator astabil. Lebar pulsa, $t_{3}$, keluaran SN74121 ini ditentukan dari nilai $R_{3}$ dan $C_{3}$ (Gambar 1.c) sesuai Persamaan 3. Dengan nilai $R_{3}$ dan $C_{3}$ masing-masing adalah 4,7 ohm dan $4,7 \times 10^{-12} \mathrm{~F}$ maka lebar pulsa, $t_{3}$ paling kecil adalah 75 nanodetik. Resistor $R_{3}$ dipasang potensiometer untuk pengaturan lebar pulsa hingga 75 nanodetik. 


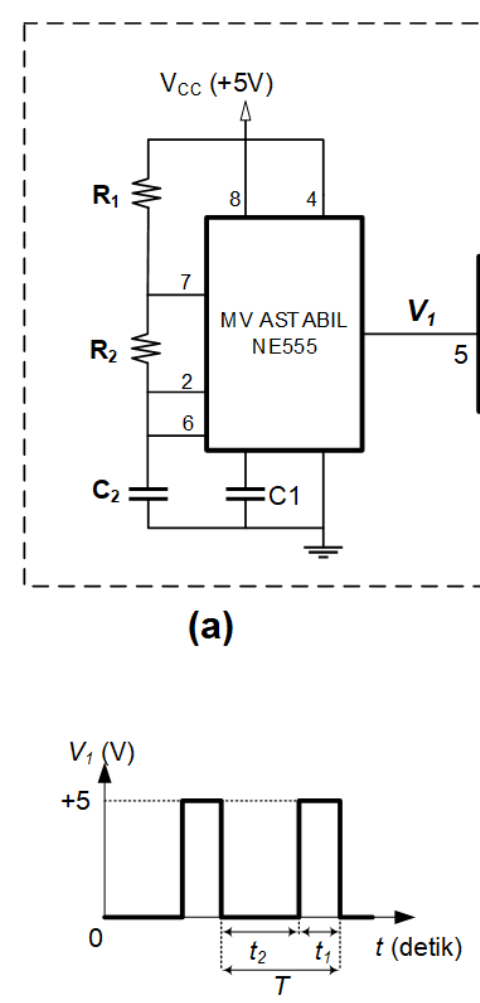

(b)

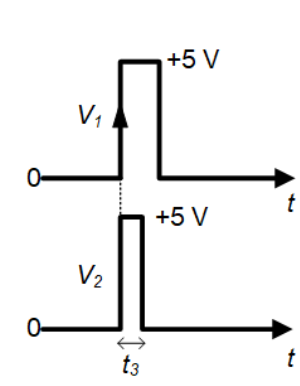

(c)

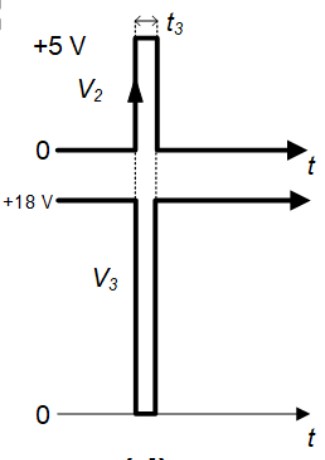

(d)

Gambar 1. Rangkaian generator pulsa orde nanodetik (a) rangkaian lengkap generator pulsa, (b) bentuk pulsa keluaran multivibrator astabil NE555, diagram pewaktuan dan bentuk sinyal masukan dan keluaran rangkaian (c) multivibrator monostabil one-shot SN74121 dan (d) pemicu Schmitt membalik MC33151

$$
t_{3}=0,33 \times R_{3} \times C_{3}
$$

Pulsa keluaran monostabil multivibrator selanjutnya dimasukkan ke rangkaian pemicu Schmitt membalik yang dibangun dari MC33151. Dengan catu daya +18 V, MC33151 menghasilkan keluaran non-TTL 0 dan $+18 \mathrm{~V}$ membalik terhadap pulsa input seperti diperlihatkan Gambar 1.d. Aras tegangan $+18 \mathrm{~V}$ diperlukan untuk menggerakkan gerbang masukan MOSFET tegangan tinggi di tahap pensaklaran (switching) tegangan tinggi [14].

Seluruh bentuk pulsa diamati dan direkam menggunakan osiloskop kecepatan tinggi GW-Instek GDS2014. Laju sampling dan panjang perekaman adalah masingmasing $1 \mathrm{Msampel/detik} \mathrm{dan} 5000$ sampel. Untuk minimalisasi induktansi dan kapasitansi parasitik, rangkaian dibuat pada papan rangkaian (PCB) sisi ground (ground mounted); perhubungan menggunakan kabel koaksial BNC dan konektor RG-58 frekuensi tinggi [3]. 


\section{Hasil dan Pembahasan}

\subsection{Pulsa multivibrator astabil}

Interval repetisi pulsa penting untuk pewaktuan kemunculan pulsa. Pada mode eksitasi transduser mode pulse-echo interval repetisi perlu diatur lebih besar dari pada waktu tempuh sinyal pancar dan terima. Dengan lebar pulsa orde nanodetik, interval pulsa dibuat cukup lebar orde milidetik (sekitar 1 milidetik). Gambar 2 memperlihatkan bentuk pulsa di keluaran multivibrator astabil NE555. Terlihat bentuk pulsa kotak aras TTL dengan nilai $t_{1}$ dan $t_{2}$ masing-masing adalah 3,404 dan 13,12 mikrodetik. Perubahan nilai $R_{1}$ dan $R_{2}$ terhadap lebar pulsa $t_{1}$ dan $t_{2}$ diperlihatkan pada Gambar 2.b. Interval repetisi semakin jauh jika nilai $R_{2}$ diperbesar tanpa mengubah lebar $t_{1}$. Hasil ini sesuai dengan Persamaan 3 dan 4 . Dengan pengaturan nilai ini, interval repetisi dapat diatur tanpa memengaruhi lebar pulsa.

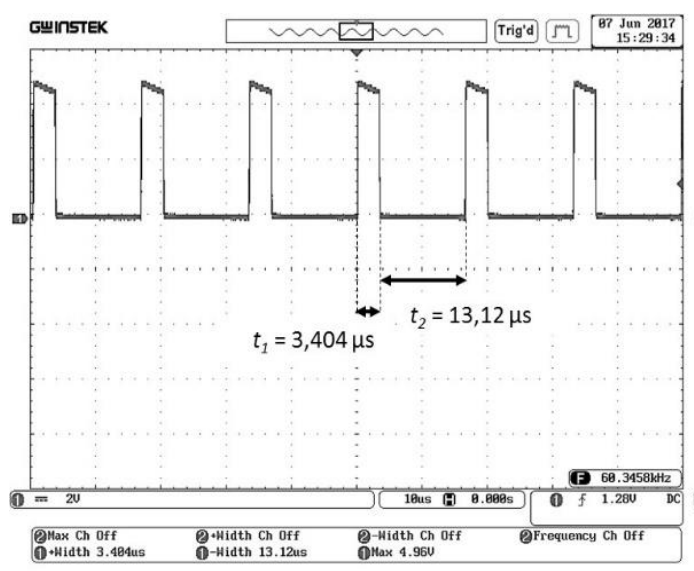

(a)

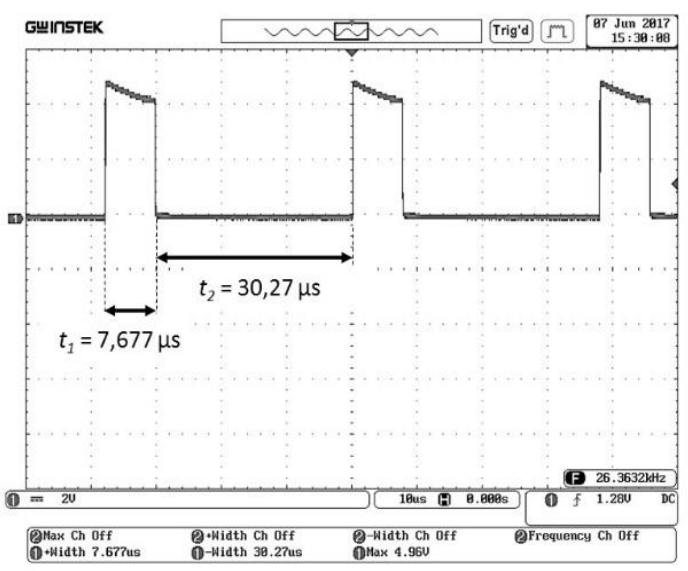

(b)

Gambar 2. Keluaran multvibrator astabil NE555 (a) bentuk pulsa dan (b) pengaruh interval repetisi terhadap nilai $R_{2}$

\subsection{Pulsa multivibrator monostable}

Pulsa repetitif keluaran dari multivibrator astabil NE555 menjadi sinyal pulsa masukan rangkaian pemicu Schmitt SN74121. Sinyal keluaran terhadap masukan diperlihatkan pada Gambar 3. Terlihat lebar pulsa keluaran, $t_{3}$ sebesar 1,043 mikrodetik sesuai dengan perhitungan Persamaan 5 nilai $R_{3}$ dan $C_{3}$ masing $22 \mathrm{k} \Omega$ dan 47 pikofarad, $t_{3}=R_{3} . C_{3}=22 \mathrm{k} \Omega \times 47 \mathrm{pF}=1$ mikrodetik. Lebar pulsa keluaran $\mathrm{SN74121}, t_{3}$ tidak bergantung pada lebar pulsa masukkan karena SN74121 diatur pada mode kerja one-shot picu tepi-positif. Nilai $t_{3}$ ditentukan oleh nilai $R_{3}$ dan $C_{3}$. Pulsa keluaran sefasa (tak-membalik) terhadap masukan. Ini karena sinyal keluaran diambil dari pin keluaran tak-membalik Q (kaki 6). Sinyal keluaran terjadi ketika tepi positif pulsa masukan. 
Multivibrator SN74121 memiliki tiga masukan, yaitu: dua masukan picu tepinegatif, A1 dan A2 (kaki 3 dan 4), dan satu masukan picu tepi-positif, B (kaki 5). Kedua masukan picu tepi-negatif A1 dan A2 dihubungkan ke ground sedangkan masukan diambil dari kaki B, merupakan masukan pemicu Schmitt picu tepi-positif. Berdasarkan lembar data teknis (datasheet), pengaturan ini menyatakan bahwa picu tepi-negatif ditakmampukan (disabled) dan picu tepi-positif dimampukan (enabled). Dengan kata lain, SN74121 diatur dalam mode kerja one-shot multivibrator picu tepi-positif. Oleh karena itu, pada Gambar 3 terlihat bahwa sinyal pulsa keluaran muncul ketika tepi-positif sinyal masukan.

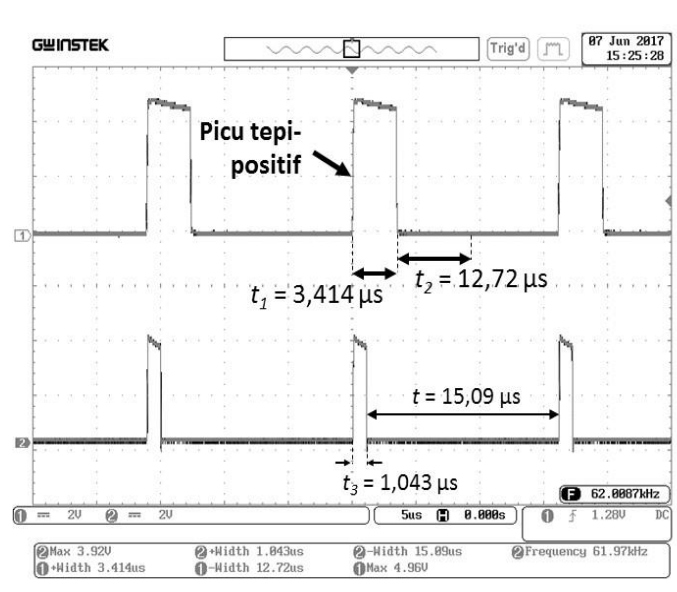

(a)

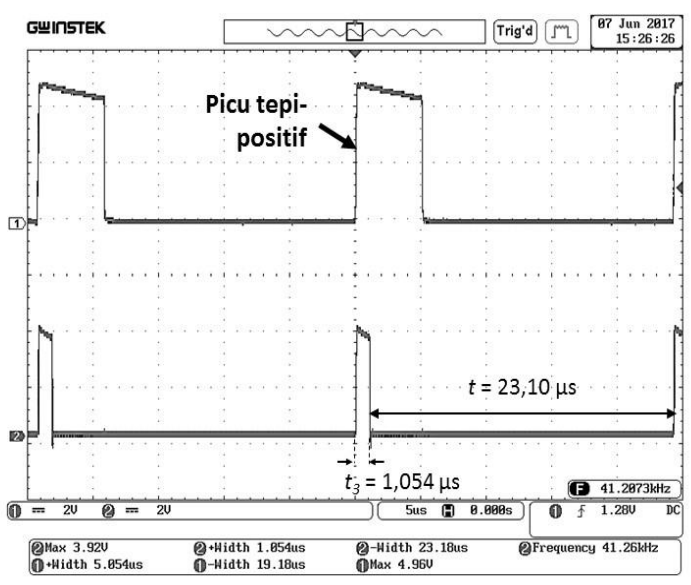

(b)

Gambar 3. Pulsa keluaran dari multvibrator monostabil (one-shot) SN74121 yang aktif pada picu tepi-positif (a) minimum lebar pulsa dan (b) pengubahan lebar pulsa dari $R_{2}$

\subsection{Konversi aras tegangan pulsa}

Seperti terlihat dalam Gambar 1, pulsa repetitif tegangan tinggi dihasilkan dengan cara mencacah (chopping), tegangan tinggi DC oleh sebuah rangkaian pensaklaran (switching) berupa MOSFET tegangan dan kecepatan tinggi. Pada rangkaian ini akan digunakan MOSFET kanal-N. Umumnya, pensaklaran MOSFET kanal-N dilakukan dengan memberikan sinyal bias pada kaki $\mathrm{G}$ (gate) sebesar maksimum +20 V. Oleh karena itu, keluaran rangkaian pulsa aras TTL dari SN74121 perlu dikonversi menjadi non-TTL $+18 \mathrm{~V}$ (kurang dari $+20 \mathrm{~V}$ ).

Gambar 4 memperlihatkan sinyal keluaran dari rangkaian pemicu Schmitt membalik MC33151. Aras tegangan keluaran adalah 0 dan $+18 \mathrm{~V}$ sesuai pengaturan catu daya. Fasa sinyal keluaran terbalik terhadap sinyal masukan dan muncul ketika picu-positif masukan. Ini karena MC33151 bekerja sebagai pembalik dan merupakan penguat pemicu Schmitt. Lebar pulsa keluaran, $t_{3}$ adalah 75 nanodetik sama dengan lebar pulsa masukan. Pulsa keluaran ini selanjutnya akan digunakan untuk menggerakkan rangkaian MOSFET kanal-N tegangan tinggi guna pembangkitan pulsa pendek tegangan tinggi. 


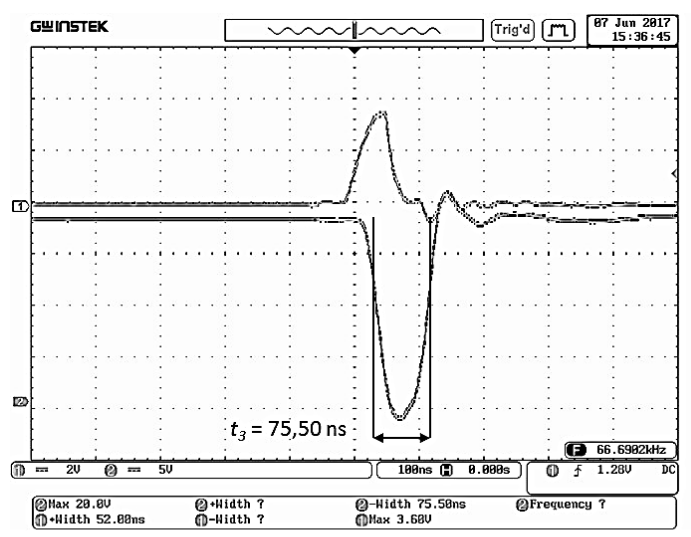

(a)

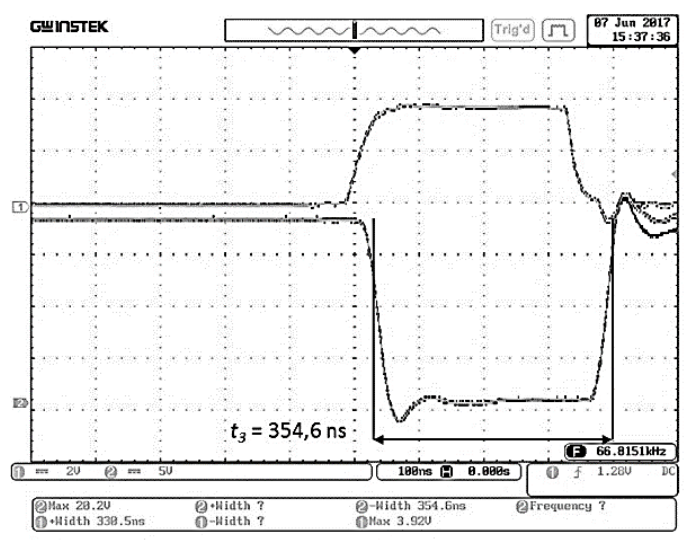

(c)

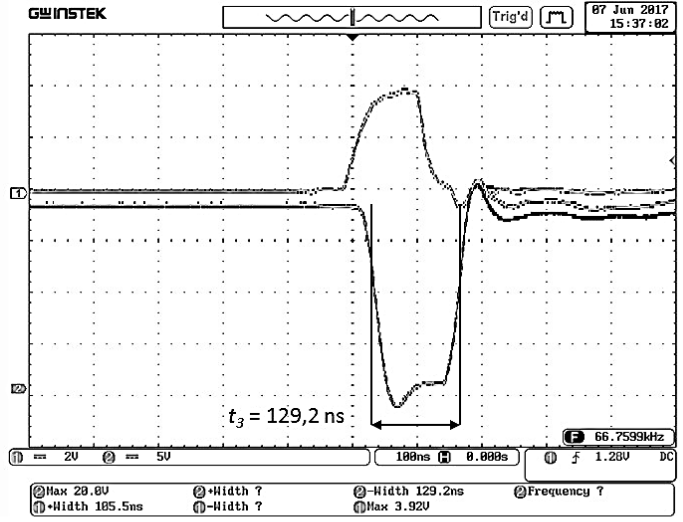

(b)

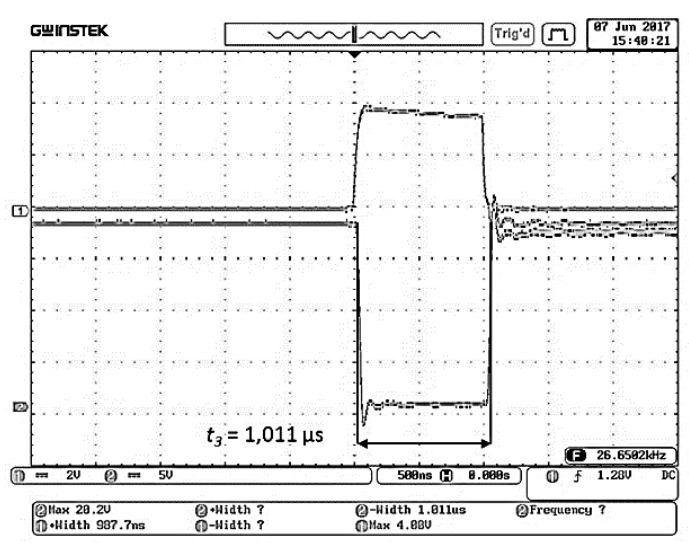

(d)

Gambar 4. Pulsa dari masukan dan keluaran rangkaian Schmitt trigger membalik MC33151

\section{Kesimpulan}

Berdasarkan hasil pengujian dapat disimpulkan bahwa rangkaian generator dapat membangkitkan pulsa penggerak aras non-TTL 0 dan $+18 \mathrm{~V}$ dengan lebar pulsa paling singkat 75 nanodetik. Interval repetisi dapat diatur hingga paling besar 1,011 mikrodetik. Pulsa ini cukup untuk menggerakkan MOSFET rangkaian switching tegangan tinggi di tingkat berikutnya.

\section{Ucapan terima kasih}

Penelitian ini didanai oleh Kemenristekdikti melalui skim Penelitian Unggulan Perguruan Tinggi (PUPT) Universitas Padjadjaran tahun anggaran 2017. Kami mengucapkan terima kasih kepada Kemenristekdikti atas pendanaan PUPT Universitas Padjadjaran nomor: 718/UN6.3.1/PL/2017.

\section{Daftar Pustaka}

1. R. Sundararajan, J. Shao, E. Soundarajan, J. Gonzales, A. Chaney, IEEE Transactions On Plasma Science 32 (2004) 2017-2025.

2. L. Svilainis, A. Chaziachmetovas, V. Dumbrava, Ultrasonics 53 (2013) 225231.

3. L. Svilainis, A. Chaziachmetovas, V. Dumbrava, Ultrasonics 59 (2015) 79-85.

4. A. Syafrudin, Suryono, J. E. Suseno, Berkala Fisika 11 (2008) 29-37. 
5. S. A. Kurniawan, A. Warsito dan M. Facta, Transmisi 16 (2014) 114-115.

6. Suryono, Kusminarto, G.B. Suparta, Rancang bangun pembangkit pulsa ultrasonik untuk material padat berbasis mikrokontroler, Prosiding pertemuan ilmiah XXIV HFI Jateng \& DIY 2010, Semarang, 247-251.

7. S. Krishnaveni, V. Rajini, Indian Journal of Science and Technology 8 (2015) $1-5$.

8. A. Chaney, R. Sundararajan, IEEE Transactions On Plasma Science 32 (2004) 1919-1924.

9. Y. Guo, G. Zhu, Novel Design and Implementation of Ultra-wideband Pulse Generator Based on Avalanche Transistor, PIERS Proceedings, Guangzhou, China, (2014) 25-28.

10. S. Krishnaveni, Rajini, Veeraraghavalu, R. Rangarajan, J. Electrical Systems 11-4 (2015) 407-419.

11. A. R. Tamuri, N. Bidin, Y. M. Daud, Applied Physics Research 1 (2009) 25-29.

12. H. Botella, J. Carlos, Petersen, L. Press, Andersen, Michael A. E.; Petersen, Niels H.. Petersen, Ultrafast Switching Superjunction MOSFETs for Single Phase PFC Applications, Proceedings of Twenty-Ninth Annual IEEE Applied Power Electronics Conference and Exposition, Denmark (2014) 143-149.

13. S. A. Jaffar, K. Malakondaiah, Y.B. Gandole, International Journal Of Innovative Research In Electrical, Electronics, Instrumentation And Control Engineering 4 (2016) 88-90.

14. D. Campbell, J. Harper, V. Natham, F. Xiao, R. Sundararajan, A Compact High Voltage Nanosecond Pulse Generator, Proc. ESA Annual Meeting on Electrostatics (2008) 1-12. 